\title{
Los animales en la escultura tardogótica del Campo de Calatrava
}

\author{
José Javier Barranquero Contento \\ Universidad de Castilla-La Mancha \\ JoseJavier.Barranquero@alu.uclm.es
}

El Campo de Calatrava nos proporciona dos pequeños conjuntos escultóricos tardogóticos en los que los animales desempeñan un papel muy importante, y que podemos contemplar en la parroquia de Santa María de Daimiel y en la del Viso del Marqués ${ }^{1}$. La iglesia de Santa María de Daimiel alberga un variadísimo repertorio de motivos vegetales que decoran dos de sus portadas, así como la mayor parte de los capiteles y ménsulas del interior. El elemento más llamativo de todo el conjunto es la imagen de gran tamaño de una sirena de doble cola que mira hacia la nave central desde los capiteles de uno de los pares de columnas que se adosan al segundo pilar del lado del evangelio. Sin embargo, este mismo pilar alberga otras dos representaciones de formato más pequeño que son muy interesantes desde un punto de vista iconográfico, representaciones que se labraron en los capiteles de las columnas pareadas que sostienen los arcos formeros. En concreto, el capitel en el que descansa el segundo de estos arcos nos muestra las imágenes de dos leones que aparecen colocados uno frente al otro, pero con las cabezas vueltas hacia atrás. Los animales mantienen las fauces abiertas, pero no son exactamente iguales, ya que el león de la izquierda posee una enorme lengua de la que carece su compañero. Junto a este animal de anatomía peculiar, en el extremo del capitel, podemos ver un ser de rasgos grotescos que mira hacia el león y que parece huir de él [1] ${ }^{2}$. La contraposición en la misma escena de un animal como el león y de un ser monstruoso no deja lugar a dudas, estaríamos ante una representación que hace hincapié en el papel apotropaico del felino.

El capitel en el que apea el siguiente arco formero alberga una representación de lo que parece el momento previo a la matanza del cerdo, ya que nos encontramos con dos hombres que sujetan a uno de estos animales tirando del hocico y del rabo [2]. Las imágenes de la matanza del cerdo son habituales en los mensarios medievales, pero en este caso nos encontramos con una escena desprovista de cualquier connotación temporal que ante todo trataría de reflejar la importancia de este animal en la dieta de la época. Una escena que serviría de contrapunto perfecto a la representación de los leones que podemos contemplar en el capitel opuesto, representación que hace hincapié en el papel simbólico del animal.

Finalmente, el edificio alberga la imagen de otro animal que, en este caso, ocupa una ménsula situada a los pies de la iglesia, en el lado de la epístola. Se trata de una liebre o un conejo que parece estar comiendo de la vegetación que hay a su lado. Los lepóridos son animales de significado ambivalente que se han utilizado para representar la lujuria, pero también la vigilancia, por la creencia de que dormían con los ojos abiertos (Rodríguez, 2011: 12). Un significado este último que se adapta a la representación que estamos analizando por encontrarse en el mismo tramo de la nave en el que se abre la portada de la epístola.

La parroquia del Viso del Marqués nos ofrece un interesante repertorio de motivos vegetales y heráldicos, pero el elemento más importante de su decoración es la representación de la caza del jabalí que se desarrolla a lo largo de las bandas que rematan los pilares que sostienen el arco de acceso al ábside, representación que resulta particularmente interesante por la cantidad y variedad de personajes que aparecen representados ${ }^{3}$. La escena se lee de izquierda a derecha, comenzando por la zona exterior del lado del evangelio y continuando hacia el interior de la capilla mayor. Su desarrollo prosigue en el lado de la epístola, por el interior del ábside, para terminar en la zona que podemos contemplar desde el cuerpo de la iglesia. La composición comienza con la imagen de un animal que ha perdido la cabeza, aunque si comparamos su aspecto con el de 

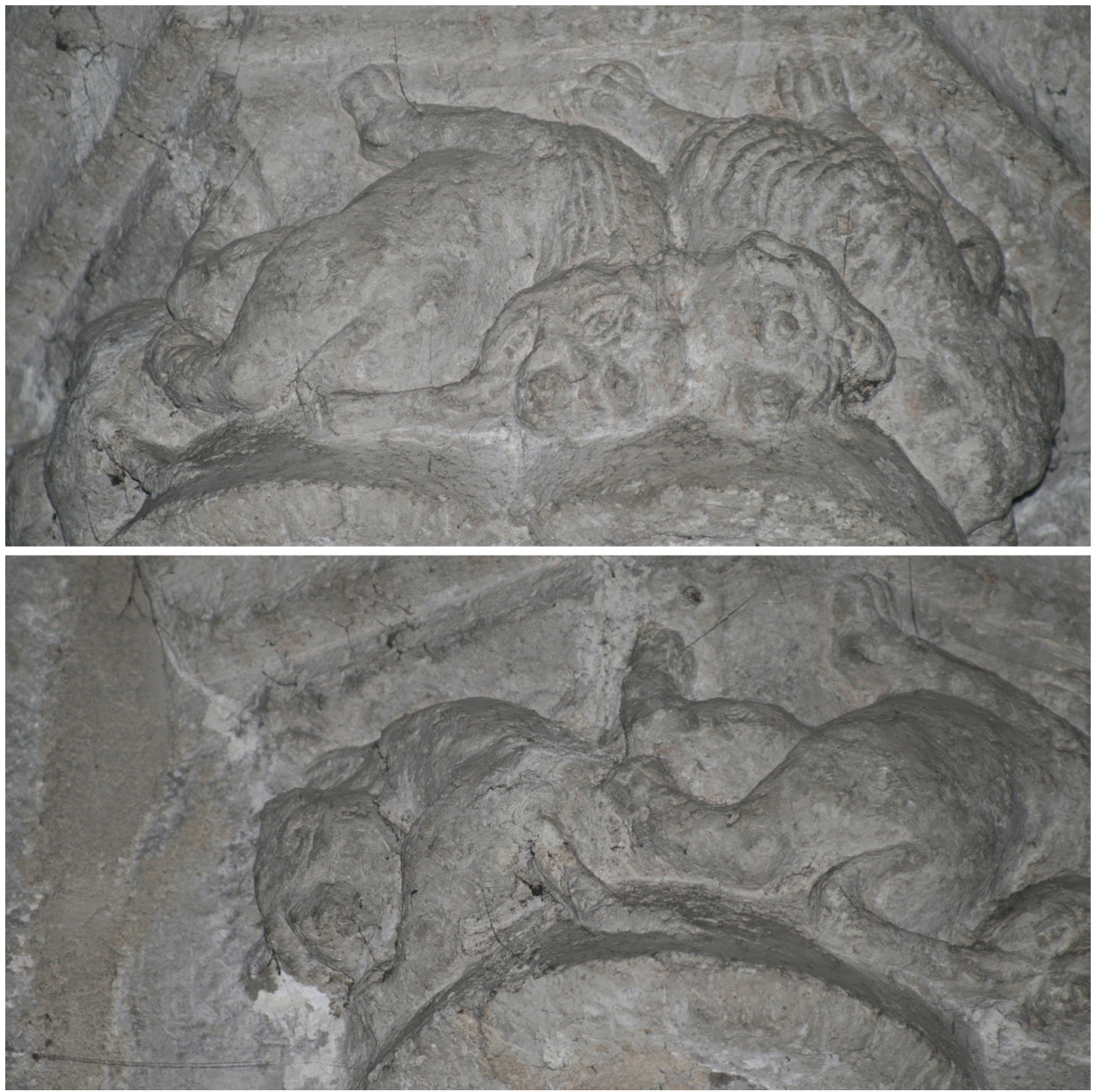

1. Parroquia de Santa María (Daimiel). Capitel. Arriba: Leones. Abajo: Ser de rasgos grotescos

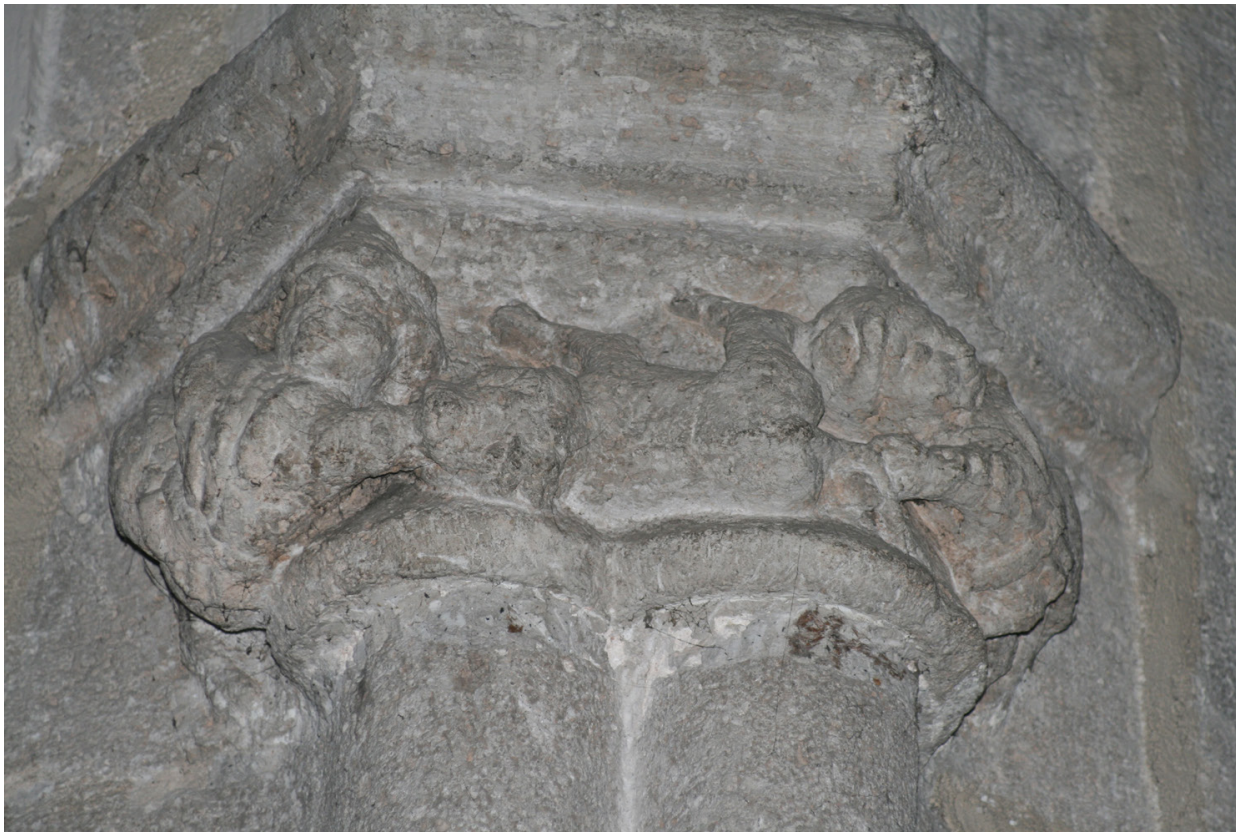




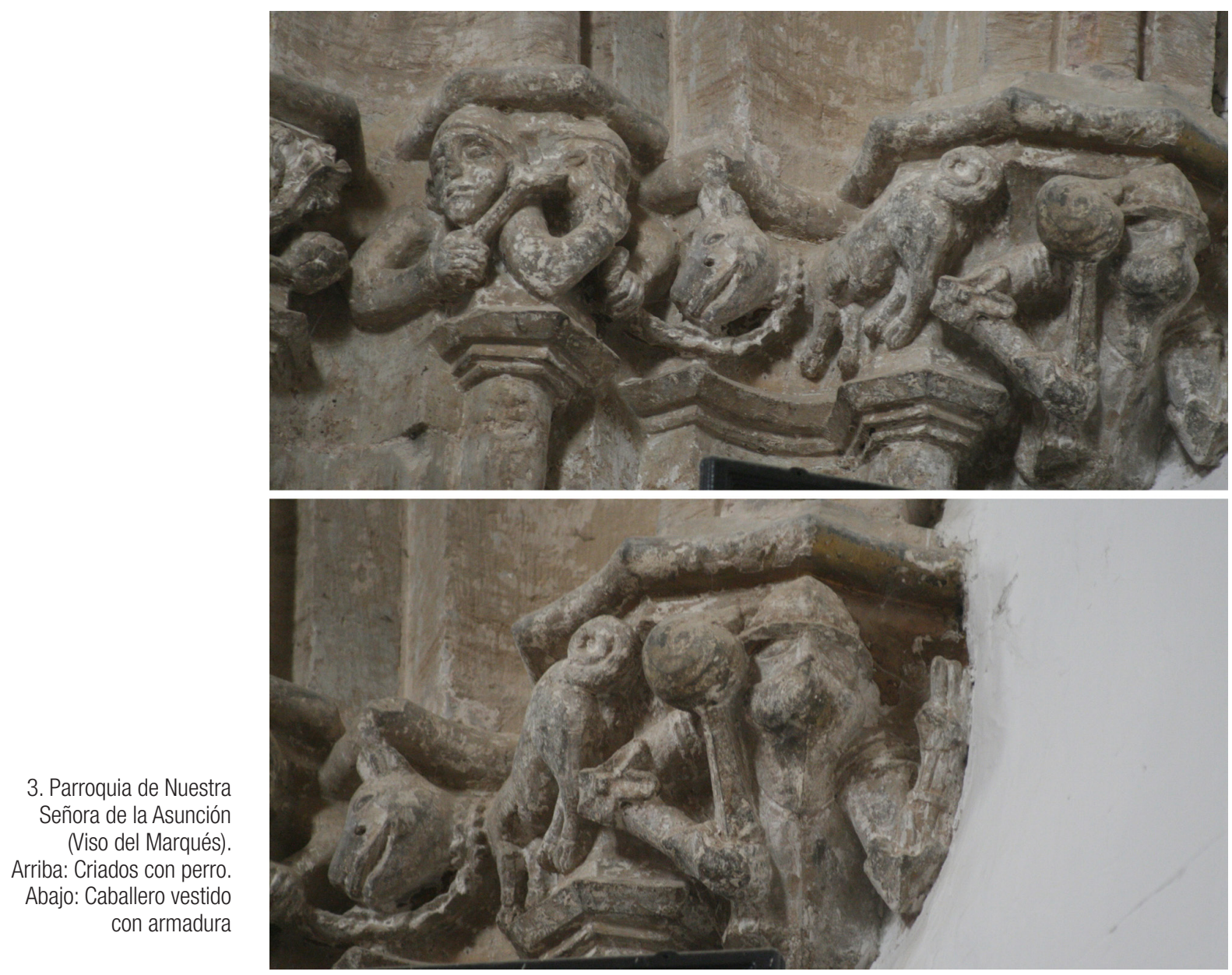

otras representaciones que aparecen en la escena podríamos asegurar que se trata de un perro. A continuación podemos ver un hombre que va tocado con una especie de casco puntiagudo y que señala con el dedo índice de su mano derecha hacia el animal que podemos ver a su lado. Se trata de un perro de orejas puntiagudas que parece salir de la vegetación que aparece a la derecha. Tras la decoración vegetal, ya en el interior de la capilla mayor, nos encontrarnos con otros dos hombres. El primero sostiene un objeto alargado, probablemente una vara, mientras que el segundo se lleva la mano a la boca, al tiempo que sujeta una cadena de la que lleva atado a un perro. La decoración de esta zona termina con la imagen de un caballero ataviado con casco y armadura que sostiene una gran maza con su mano izquierda mientras levanta la derecha, mostrándonos su palma [3].
La escena continúa en el lado de la epístola con la imagen de un caballero, ataviado también con una armadura, que empuña un objeto con la mano derecha, probablemente una espada o una daga ${ }^{4}$, mientras sujeta por una oreja la cabeza de un jabalí, exhibiéndola a modo de trofeo. Acto seguido nos encontramos con un criado que azuza a un perro con una rama. El perro, a su vez, se abalanza sobre la cabeza de otro jabalí que sale de la vegetación [4]. La composición continúa con otros dos perros que asoman las cabezas entre los matorrales, enseñando los dientes, y termina más allá con dos imágenes mutiladas. La primera es una representación humana de la que tan solo se ha conservado parte del brazo derecho; aunque, a juzgar por su vestimenta, se trataría de un criado que formaba parte de la partida de caza. La segunda, que cierra por completo la composición, parece un animal, pero es imposible identificarla por el estado que presenta. 

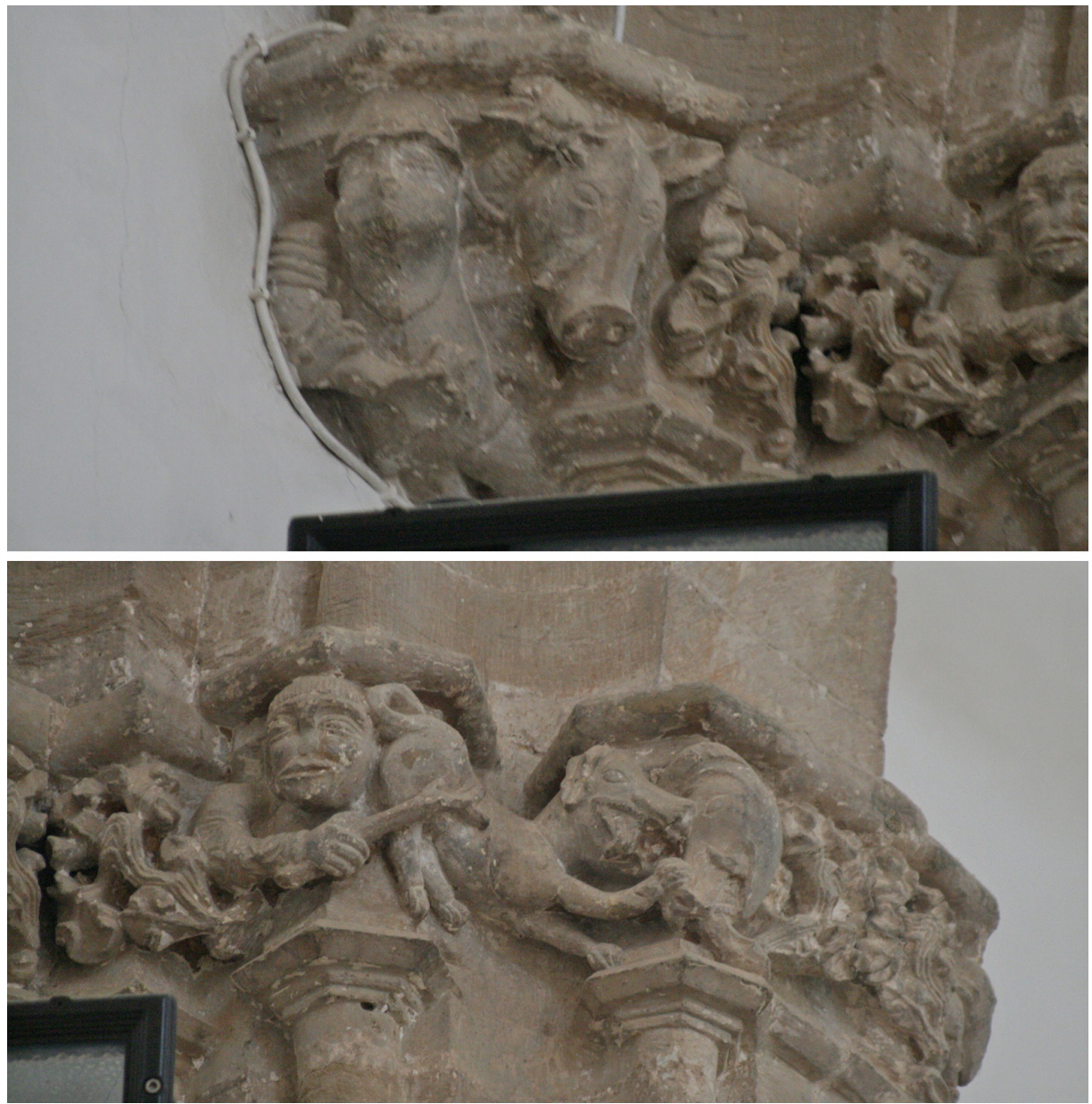

4. Parroquia de Nuestra Señora de la Asunción Viso del Marqués). Arriba: Caballero sujetando la cabeza de un jabalí. Abajo: Criado azuzando a un perro que se enfrenta a otro jabalí
Las escenas de caza son relativamente abundantes dentro del arte religioso medieval, y el jabalí suele ser una de las presas favoritas. José Luis Hernando Garrido recoge un buen número de ellas (2003: 115-118), y lo mismo hizo Carmen Manso para el contexto gallego (2000: 231 253). Este tipo de escenas pueden aparecer en las portadas, en los capiteles del interior del cuerpo e incluso en la capilla mayor del edificio, tal y como ocurre en la parroquia del Viso, y su complejidad varía enormemente, encontrándonos con representaciones en las que aparece un solo cazador enfrentándose a un jabalí o, como en el caso que nos ocupa, con recreaciones de una auténtica montería. No obstante, y desde un punto de vista formal, la representación del Viso presenta una particularidad que la diferencia de la mayor parte de las representaciones de este tipo, y es que los cazadores van ataviados como guerreros, ves- tidos con armaduras, algo completamente inusual en una partida de caza ${ }^{5}$.

La presencia de la caza del jabalí en la decoración de los edificios religiosos se ha puesto en relación con el mecenazgo desarrollado por determinados linajes nobiliarios, siendo paradigmático el caso de los Andrade. Sin embargo, cabría preguntarse por qué se eligió este tipo de representaciones para edificios que no estaban vinculados con ninguna casa noble, como la iglesia del Viso ${ }^{6}$. A nuestro juicio, la decisión de labrar una montería del jabalí en esta parroquia del Campo de Calatrava estaría relacionada con su carácter simbólico que ejemplificaría la lucha del bien contra el mal, carácter que estaría justificado por la naturaleza negativa o diabólica que tenía el jabalí en el contexto cristiano bajomedieval. Esta condición, que ha sido estudiada por Michel Pastoureau (2006: 78-81), queda acreditada en composiciones artísticas como las pin- 
turas de la Sala Capitular de la Catedral de Toledo realizadas por Juan de Borgoña. Allí, dentro de la representación del Juicio Final, en el eje central de la composición y bajo la figura de
Cristo, podemos contemplar a un jabalí de rasgos humanizados que actúa como animal infernal, agarrando por el pelo a una mujer que sale de su sepultura.

\section{Notas}

1 Se trata de dos edificios que tuvieron que levantarse a lo largo del siglo XV o principios del XVI, aunque todavía no se ha realizado ningún estudio sobre su fábrica que precise las fechas de construcción.

2 El relieve posee además la particularidad de mostrarnos a los leones cabeza abajo, mientras que el ser de rasgos monstruosos se dispone de manera convencional.

3 El ábside alberga también los símbolos de San Juan y San Lucas (el águila y el toro alado) que aparecen en las ménsulas del testero.

4 Tanto la hoja como parte de la mano se han perdido, pero parece intuirse la parte inferior del mango y el pomo del arma.

5 Alfredo Erias (1999: 317-378) reproduce un buen número de representaciones de la caza del jabalí del ámbito portugués y gallego, y en ninguna de ellas nos encontramos con un cazador vestido con armadura.

6 La iglesia de Santo Domingo de Pontevedra sería uno de esos recintos en los que aparece este tipo de escenas que no estaría vinculado con una figura nobiliaria. Carmen Manso también se preguntó por las razones que motivaron la incorporación de este tipo de representaciones en algunos edificios de Galicia, decorando además espacios muy distintos, y explicó su presencia por la evolución de los diferentes talleres gallegos. Sin embargo, este planteamiento no terminaría de explicar por qué se eligió este tipo de representaciones para decorar un recinto religioso, sobre todo si no estaba vinculado con una casa nobiliaria, como los Andrade, que justificase su presencia.

\section{Bibliografía}

ERIAS MARTíNEZ, Alfredo (1999), «La eterna caza del jabalí», Anuario brigantino, n. ${ }^{\circ} 22$, pp. 317-378.

HERNANDO GARRIDO, José Luis (2003), «Apuntes sobre la caza en el arte medieval hispano», Codex aquilarensis: Cuadernos de investigación del Monasterio de Santa María la Real, n. ${ }^{19}$, pp. 105-126.

MANSO PORTO, Carmen (2000), «El mundo profano en la imaginería gótica de los conventos mendicantes gallegos: la caza», Boletín del Museo Arqueológico Nacional, tomo 18, n. ${ }^{0}$ 1-2, pp. 231-253.

PASTOUREAU, Michel (2006), Una historia simbólica de la Edad Media Occidental, Katz Barpal Editores, Madrid.

RODRíGUEZ PEINADO, Laura (2011), «Los conejos y las liebres», Revista Digital de Iconografía Medieval, vol. III, n. ${ }^{\circ}$ 5, pp. 11-21. 